\title{
Oral Hydration as a Safe Prophylactic Measure To Prevent Post-Contrast Acute Kidney Injury in Oncologic Patients with Chronic Kidney Disease (IIlb) Referred for Contrast- Enhanced Computed Tomography: Subanalysis of The Oncological Group of The NICIR Study.
}

Carmen Sebastia ( $\square$ msebasti@clinic.cat)

Hospital Clinic de Barcelona https://orcid.org/0000-0002-3153-4350

Alfredo Páez-Carpio

Hospital Clinic de Barcelona

Elena Guillen

Hospital Clinic de Barcelona

Blanca Paño

Hospital Clinic de Barcelona

JoanAlbert Arnaiz

Hospital Clinic de Barcelona

Angel Luís de Francisco

Hospital Universitario Marques de Valdecilla

Carlos Nicolau

Universitat de Barcelona

Laura Oleaga

Universitat de Barcelona

\section{Research Article}

Keywords: Acute renal event, water, lodinated contrast media, lodine / adverse effects, cancer, Contrast induced acute kidney injury, Contrast-induced nephopathy, Computed tomography

Posted Date: August 13th, 2021

DOI: https://doi.org/10.21203/rs.3.rs-729538/v1

License: (c) (i) This work is licensed under a Creative Commons Attribution 4.0 International License. Read Full License

Version of Record: A version of this preprint was published at Supportive Care in Cancer on October 6th, 2021. See the published version at https://doi.org/10.1007/s00520-021-06561-7. 


\section{Abstract \\ Background}

The objective of this study is to evaluate oral hydration compared to intravenous (i.v.) hydration in the prevention of post-contrast acute kidney injury (PC-AKI) in the oncologic subgroup of patients with stage IIlb chronic kidney disease (CKD) included in the NICIR study referred for elective contrast-enhanced computed tomography (CE-CT).

\section{Material and Methods}

We performed a retrospective subanalysis of the oncological subgroup (174/228 patients, $74 \%$ ) from a continuous prospective database of patients included in the recently published non-inferiority NICIR study. Patients received prophylaxis against PC-AKI with either oral hydration $(500 \mathrm{~mL}$ of water two hours before and $2000 \mathrm{~mL}$ during the 24 hours after CE-CT) or i.v. hydration (sodium bicarbonate $(166 \mathrm{mmol} / \mathrm{L}) 3 \mathrm{~mL} / \mathrm{kg} / \mathrm{h}$ starting one hour before and 1 $\mathrm{mL} / \mathrm{kg} / \mathrm{h}$ during the first hour after CE-CT). The primary outcome was to compare the proportion of PC-AKI in the first 48 to 72 hours after CE-CT in the two hydration groups. Secondary outcomes were to compare persistent PC-AKI, the need for hemodialysis, and the occurrence of adverse events related to prophylaxis in each group.

\section{Results}

Of 174 patients included in the subanalysis, 82 received oral hydration and 92 received i.v. hydration. There were no significant differences in clinical characteristics or risk factors between the two study arms. Overall the PC-AKI rate was $4.6 \%$ (8/174 patients), being $3.7 \%$ in the oral hydration arm (3/82 patients) and 5.4\% (5/92 patients) in the i.v. hydration arm. The persistent PC-AKI rate was 1.8\% (1/82 patients) in the oral hydration arm and 3.3\% (3/92 patients) in the i.v. hydration arm. No patient required dialysis during the first month after CE-CT or had adverse effects related to the hydration regime.

\section{Conclusion}

In oncological patients with stage IIIb CKD referred for elective CE-CT, the rate of PC-AKI in those receiving oral hydration did not significantly differ from that of patients receiving i.v. hydration.

\section{Background}

Intravenous (i.v.) non-ionic iodinated contrast media is commonly used in computed tomography (CT) to evaluate oncologic patients. Contrast-enhanced computed tomography (CE-CT) plays an important role in the natural history of patients with cancer. CE-CT is essential to correctly characterize and stage the disease and to monitor response to oncological treatments and the risk of progression or relapse during follow-up.

Nephrotoxicity by iodinated contrast media, known as post-contrast acute kidney injury (PC-AKI), is defined as an increase in serum creatinine $(\mathrm{sCr}) \geq 0.3 \mathrm{mg} / \mathrm{dl}(26.5 \mu \mathrm{mol} / \mathrm{l})$ or $\geq 1.5$ times the baseline level occurring within $48-72$ hours of iodinated contrast media administration, in the absence of concurrent causes [1]. Pre-existing chronic kidney disease (CKD), dehydration, and acute kidney disease (AKI) are the most critical patient-related PC-AKI risk factors [2].

It is widely accepted that oncological patients have a higher risk of developing AKI, which may be as high as $17.5 \%$ at 1 year and up to $27 \%$ at 5 years after cancer diagnosis [3]. Age, type of tumour, type of oncologic treatment, use of 
nephrotoxic agents, dehydration, pre-existing kidney disease, and iodinated contrast media nephrotoxicity, among other factors, may influence the presence or absence of AKI in these patients [4].

With the increase in life expectancy there has been a rise in the number of cancer patients, many of whom have multiple risk factors leading to impaired renal function (diabetes, hypertension, cardiovascular diseases, nephrotoxic medications, among others). Moreover, the mechanism for the development of AKI may also depend on the type of tumour. Some, such as haematological malignancies, may cause AKI due to an overproduction and filtration of toxic light chains (leading to tubular injury), infiltration of the renal parenchyma, or due to their association with secondary glomerulonephritis. Other tumours, especially those of nearby organs, can directly invade the urinary tract, causing obstructive nephropathy. Furthermore, some patients may develop AKI after undergoing partial or total nephrectomy or urinary diversion. Finally, multiple pathophysiological mechanisms related to cancer itself, such as volume depletion, sepsis or several paraneoplastic syndromes, may cause AKI [4].

Nephrotoxicity by cancer therapies is another aspect that must be taken into account because of its increasing importance in clinical practice. Conventional chemotherapy with cytotoxic agents may cause kidney toxicity mainly by tubular excretion or vascular damage. New recently developed oncology drugs block specific molecules involved in tumour growth and progression (targeted therapy), thus minimising the side effects of conventional chemotherapy. Nevertheless, such signalling pathways are also active in a healthy organism, and their inhibition may be accompanied by side effects. In this regard, wide ranges of toxicities affecting various parts of the nephron have been reported with these novel targeted therapies, one of the most common disorders being acute interstitial nephritis. In this regard, both conventional and targeted therapies can affect any segment of the nephron [5].

In addition to the above, cancer patients need consecutive imaging tests to monitor disease progression, thus receiving repeated exposure to iodinated contrast [6]. However, iodinated contrast media have historically been avoided in patients with reduced kidney function due to the perceived risk of PC-AKI. This circumstance may be detrimental to these patients, given the delay in diagnosis, staging, and follow-up. Furthermore, recent articles based on propensity score matching studies have stated that PC-AKI has not only been overestimated but may even be nonexistent [7][8][9] [10].

Hydration, either with i.v. saline or bicarbonate, is currently the cornerstone of PC-AKI prophylaxis [11]. However, oral hydration may also be an option in the prophylaxis of PC-AKI, as we stated in the results of our NICIR trial, published recently in this journal, and in a recently published meta-analysis [12][13].

The NICIR study was the first prospective randomised phase III non-inferiority study to demonstrate that oral hydration is non-inferior to i.v. hydration in the prevention of PC-AKI in patients with stage IIIb CKD referred for elective CE-CT[12]. One hundred seventy-four of the patients enrolled in the aforementioned NICIR study were oncologic patients. The present retrospective analysis aims to determine whether oral hydration is effective in the prevention of PC-AKI in the subgroup of oncologic patients.

\section{Material And Methods}

We retrospectively analysed the subgroup of oncological patients of the NICIR study obtained from a continuous prospective patient database. The NICIR study included patients of both genders over 18 years of age with stage IIIb CKD referred for elective CE-CT. Stage IIIb CKD was defined as an estimated glomerular filtration rate (eGFR) between 30 and $44 \mathrm{~mL} / \mathrm{min} / 1.73 \mathrm{~m} 2$, determined by the Modification of Diet in Renal Disease formula[14]. The exclusion criteria were: refusal to participate in the study, pregnancy and lactation, associated AKI, contraindication for hydration or iodinated contrast agent administration, and more than one i.v. iodinated contrast test performed within 48-72 hours. 
This retrospective study was approved by the Institutional Review Board and the Ethical Committee of our institution. Signed consent was not needed for this retrospective analysis. Nonetheless, all the patients included had voluntarily provided consent for participation in the previous prospective trial.

The following data were retrospectively obtained from the electronic medical records of all the patients: age, gender, risk factors associated with AKI (diabetes, hypertension, cardiovascular disease), tumour type, oncologic disease status, active oncological treatment, and nephrotoxic medications, differentiating between non-oncological and oncological treatments. Finally, we recorded SCR and eGFR at baseline (at least 3 months before CE-CT) and between 48 and 72 hours after CE-CT.

Patients received one of these prophylactic therapies based on schedules published in the literature [15][16]:

1- Oral hydration: $500 \mathrm{~mL}$ of water two hours before CE-CT and $2000 \mathrm{~mL}$ in the following 24 hours after the scan.

2- i.v. hydration: sodium bicarbonate $(166 \mathrm{mmol} / \mathrm{L}) 3 \mathrm{~mL} / \mathrm{kg} / \mathrm{h}$ starting one hour before CE-CT and sodium bicarbonate (166 mmol/L) $1 \mathrm{~mL} / \mathrm{kg} / \mathrm{h}$ during the hour after CE-CT.

For the CE-CT, all patients received $100 \mathrm{~mL}$ of the non-ionic hypotonic iodinated contrast agent lohexol (Omnipaque $300 \mathrm{mg} \mathrm{l} / \mathrm{mL}$ i.v. solution, GE Healthcare Bio-Sciences, S.A.U).

Differences between baseline and post-examination SCR values were assessed to evaluate the presence of PC-AKI, which was defined as an increase in $\mathrm{SCR} \geq 0.3 \mathrm{mg} / \mathrm{dl}(26.5 \mu \mathrm{mol} / \mathrm{l})$ or $\geq 1.5$ times the baseline level occurring within 48-72 hours of iodinated contrast media administration (1). In patients who developed PC-AKI, a second SCR test was performed 15 days after CE-CT to determine the persistence or reversibility of PC-AKI. All patients with PC-AKI were referred to a consultant nephrologist to detect any concomitant cause of AKI and for close monitoring of renal function. The need for haemodialysis less than one month after CE-CT and the presence of grade 3 adverse events related to hydration were also assessed.

\section{Statistical Methods}

We checked for balance between the two arms with the Fisher's exact test and the Wilcoxon rank sum test in the oncological cohort of the NICIR study, where appropiated [12]. Rates of PC-AKI were estimated overall and by reversibility, along with $95 \%$ exact confidence intervals $(95 \% \mathrm{Cl})$. We used $95 \% \mathrm{Cl}$ to align with the standard presentation of estimates. We also estimated the upper bound of the $90 \%$ confidence interval $(90 \% \mathrm{Cl})$ to align with the planned onesided type I error rate.

After assessing balance between arms, we performed a post-hoc logistic regression analysis to assess the association between these factors and outcome. Although we had a limited number of events, we performed bivariable (arm + each unbalanced factor) and multivariable analyses (arm + all unbalanced factors), controlling for the unbalanced factors. We also assessed the interaction between arm and cancer history with PC_AKI, and provided stimates stratified by cance history.

Two-sided p-values less than 0.05 were considered statistically significant. All analyses were performed with SAS 9.4 TS1M6 (The SAS Institute, Cary, NC).

\section{Results}


The final sample of cancer patients included 174 patients, 82 of whom 82 received oral hydration and 92 received i.v. hydration. Overall, the median age was 75 years (range 35-90), and 55 patients (32\%) were female. Arms were partially balanced in baseline factors. Patients who received oral hydration were younger (Median 73, (interquartile range [IQR] 67-80)) than those who received i.v. hydration (Median 76, IQR: 70-82)), $p=0.03$. No other significant differences were found for the remaining clinical characteristics or associated risk factors $(p=0.09-0.87)$. However, baseline laboratory values differed between cohorts. Patients who received oral hydration had a higher eGFR (Median 39.0, IQR: 35.0-42.0) compared to patients receiving i.v. hydration (Median 36.0, (IQR: 32.0-40.0)), p<.001. Additionally, baseline SCR values were slightly lower in the oral hydration arm (Median 1.6, (IQR: 1.4-1.8)) compared to i.v. hydration patients (median 1.7, IQR: 1.5-1.9), $p=0.07$. Differences were also detenoted in eGFR (Median 39.5 vs. 36.0, $p<.001$ ) and SCR values (Median 1.6 vs. $1.7, p=0.013$ ) $48-72$ hours after CE-CT in the oral versus hydration groups (Table 1) (Table 2) (Fig. 1). 
Table 1

Patient and Clinical Characteristics

\begin{tabular}{|c|c|c|c|c|c|}
\hline & & All Patients & $\begin{array}{l}\text { Oral } \\
\text { Hydration }\end{array}$ & I.V. Hydration & $\begin{array}{l}\mathrm{p}- \\
\text { value }\end{array}$ \\
\hline Patients & & 174 & $82(47.1)$ & $92(52.9)$ & \\
\hline Age, years & $\begin{array}{l}\text { Median } \\
\text { (Range) }\end{array}$ & $75(35-90)$ & $73(35-90)$ & $76(58-81)$ & 0.032 \\
\hline \multirow[t]{2}{*}{ Gender } & Male & $119(68.4)$ & $57(69.5)$ & $62(67.4)$ & 0.87 \\
\hline & Female & $55(31.6)$ & $25(30.5)$ & $30(32.6)$ & \\
\hline \multicolumn{6}{|l|}{ Associated Risk Factors } \\
\hline Diabetes Mellitus & & $74(42.5)$ & $32(39)$ & $42(45.7)$ & 0.44 \\
\hline Arterial Hypertension & & $124(71.3)$ & $53(64.6)$ & $71(77.2)$ & 0.09 \\
\hline Cardiovascular Disease & & $54(31)$ & $21(25.6)$ & $33(35.9)$ & 0.19 \\
\hline $\begin{array}{l}\text { Non-oncological Nephrotoxic } \\
\text { Medications }\end{array}$ & & $113(64.9)$ & $53(64.6)$ & $60(65.2)$ & $>0.95$ \\
\hline \multicolumn{6}{|l|}{ RAS inhibitors } \\
\hline ACE-i & & $46(26.4)$ & $15(18.3)$ & 31 (33.7) & \\
\hline AllRA & & $27(15.5)$ & $18(21.9)$ & $9(9.9$ & \\
\hline \multicolumn{6}{|l|}{ Diuretics } \\
\hline Loop diuretics & & $26(14.9)$ & $12(14.6)$ & $14(15.2)$ & \\
\hline Thiazides Diuretics & & $10(5.7)$ & $7(8.4)$ & $3(3.3)$ & \\
\hline Potassium-sparing Diuretics & & $2(1.2)$ & $0(0)$ & $2(2.2)$ & \\
\hline NSAIDs & & $4(2.3)$ & $3(3,6)$ & $1(1.1)$ & \\
\hline Antivirals & & $1(0.6)$ & $0(0)$ & $1(1.1)$ & \\
\hline \multicolumn{6}{|l|}{ Laboratory Values } \\
\hline Baseline eGFR & $\begin{array}{l}\text { Median } \\
\text { (Range) }\end{array}$ & $\begin{array}{l}37.0(25.0- \\
46.0)\end{array}$ & $\begin{array}{l}39.0(28.0- \\
46.0)\end{array}$ & $\begin{array}{l}36.0(25.0- \\
44.0)\end{array}$ & $<.001$ \\
\hline eGFR 48 Hours Post-CT & $\begin{array}{l}\text { Median } \\
\text { (Range) }\end{array}$ & $\begin{array}{l}37.5(21.0- \\
63.0)\end{array}$ & $\begin{array}{l}39.5(21.0- \\
58.0)\end{array}$ & $\begin{array}{l}36.0(23.0- \\
63.0)\end{array}$ & $<.001$ \\
\hline eGFR Difference from Baseline & $\begin{array}{l}\text { Median } \\
\text { (Range) }\end{array}$ & $\begin{array}{l}0.0(-11.0- \\
28.0)\end{array}$ & $\begin{array}{l}0.0(-11.0- \\
15.0)\end{array}$ & $0.0(-9.0-28.0)$ & 0.09 \\
\hline Baseline scar & $\begin{array}{l}\text { Median } \\
\text { (Range) }\end{array}$ & $1.7(1.2-2.2)$ & $1.6(1.2-2.2)$ & $1.7(1.2-2.2)$ & 0.07 \\
\hline sCR 48 Hours Post-CT & $\begin{array}{l}\text { Median } \\
\text { (Range) }\end{array}$ & $1.7(1.0-2.7)$ & $1.6(1.0-2.7)$ & $1.7(1.1-2.5)$ & 0.013 \\
\hline sCR Difference from Baseline & $\begin{array}{l}\text { Median } \\
\text { (Range) }\end{array}$ & $0.0(-0.8-0.7)$ & $-0.0(-0.4-0.7)$ & $0.0(-0.8-0.5)$ & 0.056 \\
\hline
\end{tabular}




\section{All Patients Oral \\ Hydration \\ I.V. Hydration \\ $\mathrm{p}-$
value}

I.V.: Intravenous. CT: Computed tomography. eGFR: Estimated Glomerular Filtration Rate. sCR: Serum Creatinine. ACE-i: Angiotensin-converting enzyme inhibitors. AllRAS: Angiotensin II Receptor Antagonists. NSAIDs: Nonsteroidal anti-inflammatory drugs

Numbers represent frequency with percent of column total unless otherwise stated.

Table 2

Oncological Characteristics

\begin{tabular}{|c|c|c|c|}
\hline & All Patients & Oral Hydration & I.V. Hydration \\
\hline Patients & 174 & $82(47.1)$ & $92(52.9)$ \\
\hline \multicolumn{4}{|l|}{ Tumour Type } \\
\hline Urological & $89(51,1)$ & $40(48.8)$ & $49(53.3)$ \\
\hline Gynecological & $3(1.7)$ & $3(1.7)$ & $0(0.0)$ \\
\hline Gastrointestinal & $42(24.1)$ & $16(20.7)$ & $26(28.3)$ \\
\hline Lung & $15(8.6)$ & $8(9.8)$ & $7(7.6)$ \\
\hline Breast & $4(2.3)$ & $2(2.4)$ & $2(2.2)$ \\
\hline Others & $21(12.1)$ & $16(19.5)$ & $5(5.4)$ \\
\hline Active Oncological Treatment & $23(13.2)$ & $15(18.3)$ & $8(8.7)$ \\
\hline Active Nephrotoxic Oncological Treatment & $12(6.9)$ & $7(8.5)$ & $5(5.4)$ \\
\hline \multicolumn{4}{|l|}{ Cytotoxic agents } \\
\hline Carboplatin & $1(0.58)$ & $0(0)$ & $1(1.1)$ \\
\hline Gemcitabine & $1(0.58)$ & $1(1.2)$ & $0(0)$ \\
\hline \multicolumn{4}{|l|}{ Targeted therapies } \\
\hline Interferon-alpha 2A & $1(0.58)$ & $1(1.2)$ & $0(0)$ \\
\hline Lenalidomide & $1(0.58)$ & $1(1.2)$ & $0(0)$ \\
\hline Pembrolizumab (PD-1 inhibitor) & $5(2.9)$ & $1(1.2)$ & $4(4.4)$ \\
\hline Atezolizumab (PDL-1 inhibitor) & $1(0.58)$ & $1(1.2)$ & $0(0)$ \\
\hline Cetuximab (EGFR inhibitor) & $1(0.58)$ & $1(1.2)$ & $0(0)$ \\
\hline \multicolumn{4}{|c|}{$\begin{array}{l}\text { PD-1: programmed cell death protein-1. PDL-1: programmed death-ligand 1. VEGFR: vascular endothelial growth } \\
\text { factor.EGFR: epidermal growth factor receptor. }\end{array}$} \\
\hline
\end{tabular}

\section{PC-AKI}

Eight patients (4.6\%) experienced PC-AKI. Three patients in the oral hydration arm developed PC-AKI, resulting in a PC$\mathrm{AKI}$ rate of $3.7 \%(95 \% \mathrm{Cl}: 0.8-10.3 \%)$. In the i.v. hydration arm, the PC-AKI rate was $5.4 \%(95 \mathrm{Cl}: 1.8-12.2 \%)$, with 5 
patients developing PC-AKI (Table 2). For i.v. hydration, the upper bound limit of the $90 \% \mathrm{Cl}$ was $11.1 \%$, which covered the estimate of PC-AKI for the oral hydration arm $(3.7 \%<11.1 \%)($ Table 3$)$.

Table 3

PC-AKI Rates

\begin{tabular}{|llllll|}
\hline \multicolumn{4}{|c}{ Oral Hydration } & \multicolumn{2}{c|}{ I.V. Hydration } \\
\hline & & $\%(95 \% \mathrm{Cl})$ & $\mathrm{N}$ & $\%(95 \% \mathrm{Cl})$ & $\mathrm{N}$ \\
\hline PC-AKI & Yes & $3.7 \%(0.8-10.3 \%)$ & $3 / 82$ & $5.4 \%(1.8-12.2 \%)$ & $5 / 92$ \\
\hline Reversible PC-AKI & Irreversible & $1.2 \%(0.0-6.6 \%)$ & $1 / 82$ & $3.3 \%(0.7-9.2 \%)$ & $3 / 92$ \\
& Reversible & $2.4 \%(0.3-8.5 \%)$ & $2 / 82$ & $2.2 \%(0.3-7.6 \%)$ & $2 / 92$ \\
\hline PC-AKI: Post-Contrast Acute Kidney Injury. I.V.: Intravenous. & & \\
\hline
\end{tabular}

PC-AKI was reversible for 2 patients $(2,4 \%)$ and was irreversible in 1 patient $(1.2 \%)$ in the oral hydration arm, while in the i.v. hydration arm, PC-AKI was irreversible in 3 patients (3.3\%) and reversible in 2 patients (2.2\%) (Table 3$)$.

Not patients experienced adverse effects due to hydration, nor did they need dialysis.

Control for Confounding

In the post-hoc analyses, no significant association was found between age (odds ratio [OR]: 0.99, 95\% Cl: 0.94-1.06, p = 0.85), baseline eGFR (OR: 0.86, 95\%Cl: 0.73-1.02, $\mathrm{p}=0.09$ ) or baseline sCR values (OR: 3.48, 95\% Cl: 0.20-61.1, p = 0.39). In the bivariable models, the relationship between study arm and PC-AKI remained consistent after controlling for these unbalanced factors (OR: 0.63-0.94) (Table 4).

Table 4

Associations with PC-AKI Controlling for Unbalanced Baseline Factors

\begin{tabular}{|c|c|c|c|c|c|c|c|c|c|c|c|c|}
\hline & \multicolumn{3}{|c|}{ Univariable } & \multicolumn{3}{|c|}{ Bivariable: sCR } & \multicolumn{3}{|c|}{ Bivariable: eGFR } & \multicolumn{3}{|c|}{ Bivariable: Age } \\
\hline & OR & $\begin{array}{l}(95 \% \\
\mathrm{Cl})\end{array}$ & $\begin{array}{l}\mathrm{p}- \\
\text { value }\end{array}$ & OR & $\begin{array}{l}(95 \% \\
\mathrm{Cl})\end{array}$ & $\begin{array}{l}\mathrm{p}- \\
\text { value }\end{array}$ & OR & $\begin{array}{l}(95 \% \\
\mathrm{Cl})\end{array}$ & $\begin{array}{l}\mathrm{p}- \\
\text { value }\end{array}$ & OR & $\begin{array}{l}(95 \% \\
\mathrm{Cl})\end{array}$ & $\begin{array}{l}\mathrm{p}- \\
\text { value }\end{array}$ \\
\hline \multicolumn{13}{|l|}{ Arm } \\
\hline \multirow{2}{*}{$\begin{array}{l}\text { Oral } \\
\text { I.V. }\end{array}$} & 0.66 & $\begin{array}{l}(0.15- \\
2.86)\end{array}$ & 0.58 & 0.72 & $\begin{array}{l}(0.16- \\
3.17)\end{array}$ & 0.67 & 0.94 & $\begin{array}{l}(0.20- \\
4.34)\end{array}$ & 0.94 & 0.63 & $\begin{array}{l}(0.14- \\
2.81)\end{array}$ & 0.55 \\
\hline & REF & & & - & & & -- & & & -- & & \\
\hline $\begin{array}{l}\text { Baseline } \\
\text { SCR }\end{array}$ & 3.48 & $\begin{array}{l}(0.20- \\
61.09)\end{array}$ & 0.39 & 3.16 & $\begin{array}{l}(0.17- \\
57.37)\end{array}$ & 0.44 & - & & & - & & \\
\hline $\begin{array}{l}\text { Baseline } \\
\text { eGFR }\end{array}$ & 0.86 & $\begin{array}{l}(0.73- \\
1.02)\end{array}$ & 0.09 & -- & & & 0.87 & $\begin{array}{l}(0.73- \\
1.03)\end{array}$ & 0.10 & -- & & \\
\hline $\begin{array}{l}\text { Age, } \\
\text { years }\end{array}$ & 0.99 & $\begin{array}{l}(0.94- \\
1.06)\end{array}$ & 0.85 & -- & & & - & & & 0.99 & $\begin{array}{l}(0.93- \\
1.06)\end{array}$ & 0.76 \\
\hline
\end{tabular}

\section{Discussion}


This retrospective analysis of the data acquired during the NICIR study demonstrates that oral hydration was as effective as i.v. hydration in the prophylaxis of PC-AKI after CE-CT in the oncologic subgroup of patients with IIIb CKD of this trial. In this subgroup, the overall PC-AKI rate was 4.6\% (8 patients), with $3.7 \%$ (3 patients) in the oral hydration arm and $5.4 \%$ (5 patients) in the i.v. hydration arm.

It is important to emphasise that most patients included in this oncological subgroup of the NICIR study sample were elderly patients with multiple risk factors for AKI, as shown in Table 1. In addition, abdominal tumours were particularly prevalent in our sample (76.9\%), specifically urinary tumours (51.1\%) (Table 2). One explanation for this circumstance could be that most of these tumours and their curative treatment (surgery, targeted radiotherapy, and chemotherapy) tend to have an impact on renal function. Note that the four cases in our sample that presented irreversible PC-AKI were patients over 70 years of age with multiple associated risk factors for the development of AKI, regardless of iodinated contrast administration and method of prophylaxis, as shown in Fig. 1. As mentioned previously, the development of AKI is usually a multifactorial process. These factors are more present in oncologic patients, which exponentially increases the risk of renal toxicity in this population. [4][5]. Therefore, all cancer patients should be considered as a high-risk population for developing AKI and should be explicitly protected with prophylactic measures to avoid PC-AKI.

Some studies describe subclinical damage with reduction in the functional reserve of the kidneys in patients receiving multiple doses of iodinated contrast over an extended period of time, and this reduction in functional reserve does not translate into analytical alterations until it is well established [17]. Unfortunately, we currently do not have clinical parameters such as renal functional reserve stress tests or urinary markers to assess any eventual hidden renal damage. In this regard, the European Society of Urogenital Radiation (ESUR) guidelines recommend delaying repeated exposure of iodinated contrast media for 48 ours in patients with pre-existing CKD [18]. The European Renal Best Practice guidelines recommend that if AKI develops after contrast administration, repeat exposure should preferably be delayed until the SCR level has returned to baseline values [19]. Although a short time span between chemotherapy administration and CE-CT increases the risk of AKI [20], as far as we know, no study has specifically addressed evaluation of the risk of nephrotoxicity in patients with cancer on active treatment undergoing serial CE-CT, especially in patients on clinical trials that usually undergo repeated CE-CT with a short time period [21].

In our study, we used hypo-osmolar non-ionic iodinated contrast media, which has a higher osmolarity than plasma [6] [22]. There is controversy in the literature as the type of contrast to use in oncologic patients in order to preserve renal function. Some authors propose the use of iso-osmolar contrast in these patients, as it is less harmful to the kidney [23]. However, most radiological and clinical guidelines consider that this protection is not proven, especially when the route of administration is intravenous [11][20] [24]. Werner et al. published the first series investigating the incidence of PC-AKI with elective CE-CT in oncologic patients with CKD IIIb receiving oral hydration prophylaxis and iso-osmolar contrast, and reported $4.2 \%$ of patients developing PC-AKI [25]. These results are similar to those of our series in the oral hydration study arm, using hypo-osmolar iodinated contrast media (3.7\%). Prospective randomised studies are needed to compare the two types of contrast in order to determine whether there are significant differences between hypo-osmolar and iso-osmolar non-ionic contrast media regarding renal function protection.

Based on two trials (AMAZING, Kompas), the threshold for prophylactic i.v. hydration after i.v. injection of iodinated contrast media has recently been reduced from $45 \mathrm{ml} / \mathrm{min} / \mathrm{m}^{2}$ to $30 \mathrm{~mL} / \mathrm{min} / \mathrm{m}^{2}$ in most radiological guidelines [26] [27][11]. However, other clinical and radiological societies advocate that there is not enough evidence to lower this threshold [28]. Specifically, the Cosmai et al. white paper consensus publication in patients with cancer advises hydrating all oncologic patients with an eGFR less than $60 \mathrm{ml} / \mathrm{min} / \mathrm{m}^{2}$ before CE-CT [20]. Although studies on oral hydration are limited, preliminary evidence on this strategy suggests that it is as safe and effective as intravenous prophylaxis [29](13). Furthermore, this evidence suggests the alternative of performing a more straightforward and 
cheaper regimen for these patients, which we already perform in our hospital in all patients undergoing an elective CECT [12].

Dehydration is common in oncologic patients due to many factors associated with cancer itself and its treatment [23]. It is well established that dehydration is also a risk factor for PC-AKI. Prolonged fasting of liquids and solids usually performed before CE-CT is, in itself, a risk factor for developing PC-AKI due to the dehydration to which the patient is subjected [30]. Prolonged fasting can also amplify the stress response of patients and even cause anxiety, noncooperation, weakness, hypoglycaemia, a decline in blood pressure and severe shock reactions, especially in older cancer patients (30) [31]. In addition, patients often stop taking routine medication during fasting, which may increase the health risk for patients with hypertension or diabetes or those who require continuous medications. Recent articles published in the literature demonstrated that fasting of solid food and fluids before injection of iodinated contrast media is not needed, and specifically ingestion of clear inert fluid less than 1 hour before CE-CT rarely induced nausea and vomiting and never aspiration [32][33] ([34]. Barbosa et al. specifically studied this in cancer patients and reported no clinically or statistically significant differences in the frequency of adverse reactions in outpatients with cancer undergoing CE-CT with or without preparative fasting [30]. The latest ESUR guidelines (10.0) clear state that fasting and interruption of medication are not recommended before the administration of Ihypo- or isosmolar iodinated contrast media [18]. In our institution, the traditional fasting policy prior to CE-CT has been abolished according to this new statement in all outpatients, unless required for certain types of imaging tests.

One limitation of our series is that few patients were undergoing active oncological treatment at the time of the NICIR study and even fewer were receiving nephrotoxic oncological treatment. Therefore, our results may not be directly applicable to patients with active oncological treatment. Another significant limitation of this study is that our series corresponds to a retrospective assessment of the NICIR trial. Furthermore, our sample size was small. However, it should be noted that considering that we studied oncological patients with multiple associated risk factors and confined to a subgroup of patients with severe CKD, the incidence of PC-AKI in our study was not higher than that reported in the literature for groups with far fewer risk factors [35]. Prospective randomised studies in this subgroup of patients is needed to draw definitive conclusions in this regard.

\section{Conclusion}

Our study demonstrates the safety and efficacy of oral hydration in the prevention of PC-AKI in oncology patients These results justify the use of oral hydration in oncological patients with stage IIIb CKD undergoing elective CE-CT, until there is scientific consensus on whether or not prophylactic hydration should be performed in this subgroup of CKD patients.

\section{Abbreviations}

i.v.

intravenous

CT

Computed tomography

CE-CT

Contrast-enhanced CT

PC-AKI

Post-contrast acute kidney injury

SCR

Page 10/15 
Serum creatinine

CKD

Chronic kidney disease

AKI

Acute kidney injury

eGFR

estimated glomerular filtration rate

ESUR

European Society of Urogenital Radiology

\section{Declarations}

No disclosures of any of the authors.

\section{FUNDING:}

No funding

\section{AVAILABILITY OF DATA AND MATERIALS}

The analyzable dataset is availlable from the authors upon reasonable request, and with permission of Hospital Clinic de Barcelona database

\section{CODE AVAILABILITY}

Not applicable

\section{AUTHORS' CONTRIBUTION}

CS, JAA, CN, LO contributed to the concept and design of the study and contributed critical revision of the manuscript. CS, EG, AP were responsible for the data analysis. CS, AP, AdF were responsible for interpretation of results and drafting the masnuscript. All authors read and approved the final manuscript

\section{ETHICS APPROVAL}

All data used to perform this retrospective analysis were de-identified. This retrospective study was approved by the Institutional Review Board and the Ethical Committee of our institution (HCB/2021/0021). Signed consent was not needed for this retrospective analysis.

\section{CONSENT TO PARTICIPATE}

Not applicable

\section{CONSENT FOR PUBLICATION}

Not applicable

\section{COMPETING INTERESTS/CONFLICTS OF INTEREST}

The authors declare that they have no competing interests/conflicts of interests 


\section{ACKNOWLEDGEMENTS}

none

\section{References}

1. Molen AJ, Van Der, Reimer P, Dekkers IA, Bongartz G, Bellin M. Post-contrast acute kidney injury - Part 1: Definition, clinical features,incidence, role of contrast medium and risk factors. European Radiology; 2018;2845-55

2. van der Molen AJ, Reimer P, Dekkers IA, Bongartz G, Bellin MF, Bertolotto M et al (2018) Post-contrast acute kidney injury. Part 2: risk stratification, role of hydration and other prophylactic measures, patients taking metformin and chronic dialysis patients: Recommendations for updated ESUR Contrast Medium Safety Committee guidelines. Eur Radiol European Radiology 28:2856-2869

3. Christiansen CF, Johansen MB, Langeberg WJ, Fryzek JP, Sørensen HT. Incidence of acute kidney injury in cancer patients: A Danish population-based cohort study. Eur J Intern Med [Internet]. European Federation of Internal Medicine.; 2011;22:399-406. Available from: http://dx.doi.org/10.1016/j.ejim.2011.05.005

4. Luis de Francisco ÁM, Macía M, Alonso F, García P, Gutiérrez E, Fernando Quintana L et al. Efectos renales adversos del actual tratamiento del cáncer. N NefroPlus [Internet]. 2019;11:1-12. Available from: http://revistanefrologia.com/

5. Wang LY, Wang JN, Diao ZL, Guan YM, Liu WH (2020) Acute kidney injury in oncology patients. J Cancer 11:47004708

6. de Francisco ALM, Arias Guillén M, Pérez-Valderrama B, Sebastia C (2019) Lesión renal aguda poscontraste en pacientes con cáncer. Nefrología 39:563-567

7. Baumgarten DA, Ellis JH (2008) Contrast-Induced Nephropathy: Contrast Material Not Required? Am J Roentgenol 191:383-386

8. Mcdonald RJ, Mcdonald JS, Bida JP, Carter RE, Fleming CJ, Williamson EE et al (2013) Material - induced Nephropathy: Causal or Coincident Phenomenon ? 267:1

9. Mcdonald JS, Mcdonald RJ, Comin J, Williamson EE, Katzberg RW, Kallmes DF (2013) Frequency of Acute Kidney Injury Following Intravenous Contrast Medium Administration. A Systematic Review and 267:119-128

10. Dekkers IA. Propensity Score Matching as Controlled Trials on Acute Kidney. 2018;1-5

11. Davenport MS, Perazella MA, Yee J, Dillman JR, Fine D, McDonald RJ et al (2020) Use of Intravenous lodinated Contrast Media in Patients With Kidney Disease. Kidney Med 2:85-93

12. Sebastià C, Páez-Carpi A, Guillen E, Garcia-Cinca D, Poch E, Oleaga L et al. Oral hydration compared to intravenous hydration in the prevention of post-contrast acute kidney injury in patients with chronic kidney disease stage IIIb: A phase III non-inferiority study (NICIR study). Eur J Radiol. 2021;136

13. Zhang W, Zhang J, Yang B, Wu K, Lin H, Wang Y et al (2018) Effectiveness of oral hydration in preventing contrastinduced acute kidney injury in patients undergoing coronary angiography or intervention: A pairwise and network meta-analysis. Coron Artery Dis 29:286-293

14. Andrassy KM (2013) Comments on "KDIGO 2012 clinical practice guideline for the evaluation and management of chronic kidney disease". Kidney Int 84:622-623

15. Kooiman J, Sijpkens YWJ, De Vries JPPM, Brulez HFH, Hamming JF, Van Der Molen AJ et al (2014) A randomized comparison of 1-h sodium bicarbonate hydration versus standard peri-procedural saline hydration in patients with chronic kidney disease undergoing intravenous contrast-enhanced computerized tomography. Nephrol Dial Transplant 29:1029-1036

Page 12/15 
16. Kong D-G, Hou Y-F, Ma L-L, Yao D-K, Wang L-X. Comparison of oral and intravenous hydration strategies for the prevention of contrast-induced nephropathy in patients undergoing coronary angiography or angioplasty: a randomized clinical trial. Acta Cardiol [Internet]. 2012;67:565-9. Available from:

http://www.ncbi.nlm.nih.gov/pubmed/23252007

17. Fähling M, Seeliger E, Patzak A, Persson PB (2017) Understanding and preventing contrast-induced acute kidney injury. Nat Rev Nephrol Nature Publishing Group 13:169-180

18. Contrast Media Safety Committee. ESUR Guidelines on Contrast Agents v10.0. Eur Soc Urogenit Radiol [Internet]. 2018;0-45. Available from: http://www.esur.org/fileadmin/content/2019/ESUR_Guidelines_10.0_Final_Version.pdf

19. Fliser D, Laville M, Covic A, Fouque D, Vanholder R, Juillard L et al (2012) A European Renal Best Practice (ERBP) position statement on the Kidney Disease Improving Global Outcomes (KDIGO) Clinical Practice Guidelines on Acute Kidney Injury: Part 1: Definitions, conservative management and contrast-induced nephropathy. Nephrol Dial Transplant 27:4263-4272

20. Cosmai L, Porta C, Privitera C, Gesualdo L, Procopio G, Gori S et al. Acute kidney injury from contrast-enhanced CT procedures in patients with cancer: white paper to highlight its clinical relevance and discuss applicable preventive strategies. ESMO open [Internet]. Elsevier Masson SAS; 2020;5:e000618. Available from:

https://doi.org/10.1136/esmoopen-2019-000618

21. Faucon AL, Bobrie G, Clément O. Nephrotoxicity of iodinated contrast media: From pathophysiology to prevention strategies. Eur J Radiol [Internet]. Elsevier; 2019;116:231-41. Available from:

https://doi.org/10.1016/j.ejrad.2019.03.008

22. Sebastià C, Nicolau C, Martín de Francisco ÁL, Poch E, Oleaga L. Prophylaxis against postcontrast acute kidney injury (PC-AKI): updates in the ESUR guidelines 10.0 and critical review. Radiologia. 2020;62

23. Francisco ALM, De, Macía M, Alonso F, García P, Gutierrez E, Fernando L et al. Onco-Nefrología: cáncer, quimioterapia y ri nón. 2019;9:473-81

24. ACR Committee on drugs and contrast Media. ACR Manual on Contrast Media [Internet]. ACR Man. Contrast Media - Version 9, 2013 (2013) Available from:

http://www.acr.org/ /media/ACR/Documents/PDF/QualitySafety/Resources/Contrast

Manual/2013_Contrast_Media.pdf

25. Werner S, Bez C, Hinterleitner C, Horger M. Incidence of contrast-induced acute kidney injury (Cl-AKI) in high-risk oncology patients undergoing contrast-enhanced $\mathrm{CT}$ with a reduced dose of the iso-osmolar iodinated contrast medium iodixanol. PLoS One [Internet]. 2020;15:1-10. Available from:

http://dx.doi.org/10.1371/journal.pone.0233433

26. Nijssen EC, Rennenberg RJ, Nelemans PJ, Essers BA, Janssen MM, Vermeeren MA et al. Prophylactic hydration to protect renal function from intravascular iodinated contrast material in patients at high risk of contrast-induced nephropathy (AMACING): a prospective, randomised, phase 3, controlled, open-label, non-inferiority trial. Lancet [Internet]. Elsevier Ltd; 2017;389:1312-22. Available from: http://dx.doi.org/10.1016/S0140-6736(17)30057-0

27. Timal RJ, Kooiman J, Sijpkens YWJ, de Vries J-PPM, Verberk-Jonkers IJAM, Brulez HFH et al (2020) Effect of No Prehydration vs Sodium Bicarbonate Prehydration Prior to Contrast-Enhanced Computed Tomography in the Prevention of Postcontrast Acute Kidney Injury in Adults With Chronic Kidney Disease. JAMA Intern Med 180:533

28. Nyman U, Ahlkvist J, Aspelin P, Brismar T, Frid A, Hellström M et al. Preventing contrast medium-induced acute kidney injury. Eur Radiol [Internet]. European Radiology; 2018;5384-95. Available from: http://www.ncbi.nlm.nih.gov/pubmed/30132106\%0Ahttp://link.springer.com/10.1007/s00330-018-5678-6

29. Patschan D, Buschmann I, Ritter O. Contrast-Induced Nephropathy: Update on the Use of Crystalloids and Pharmacological Measures. Int J Nephrol. Hindawi; 2018;2018

Page 13/15 
30. Barbosa PNVP, Bitencourt AGV, Tyng CJ, Cunha R, Travesso DJ, Almeida MFA et al (2018) Preparative fasting for contrast-enhanced CT in a cancer center: A new approach. Am J Roentgenol 210:941-947

31. Li X, Liu H, Zhao L, Liu J, Cai L, Zhang L et al. The effect of preparative solid food status on the occurrence of nausea, vomiting and aspiration symptoms in enhanced CT examination: Prospective observational study. $\mathrm{Br} \mathrm{J}$ Radiol. 2018;91

32. Kim YS, Yoon SH, Choi YH, Park CM, Lee W, Goo JM (2018) Nausea and vomiting after exposure to non-ionic contrast media: Incidence and risk factors focusing on preparatory fasting. Br J Radiol 91:1-8

33. Lee B-Y, Ok J-J, Abdelaziz Elsayed AA, Kim Y, Han DH (2012) Preparative Fasting for Contrast-enhanced CT: Reconsideration. Radiology 263:444-450

34. Tsushima Y, Seki Y, Nakajima T, Hirasawa H, Taketomi-Takahashi A, Tan S et al (2020) The effect of abolishing instructions to fast prior to contrast-enhanced CT on the incidence of acute adverse reactions, 11. Insights Imaging. Insights into Imaging

35. Kooiman J, Sijpkens YWJ, De Vries JPPM, Brulez HFH, Hamming JF, Van Der Molen AJ et al (2014) A randomized comparison of 1-h sodium bicarbonate hydration versus standard peri-procedural saline hydration in patients with chronic kidney disease undergoing intravenous contrast-enhanced computerized tomography. Nephrol Dial Transplant 29:1029-1036

\section{Figures}

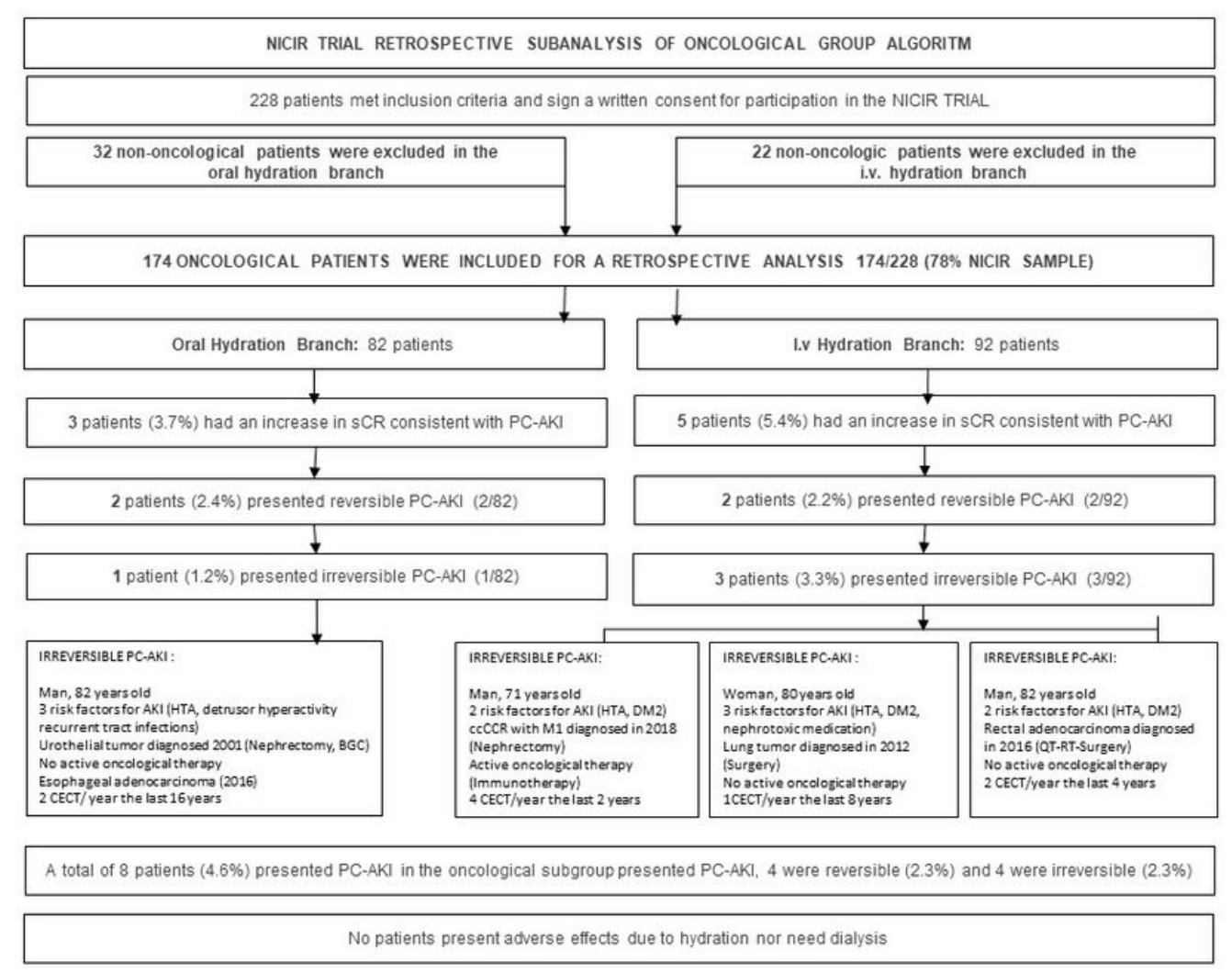

\section{Figure 1}

One explanation for this circumstance could be that most of these tumours and their curative treatment (surgery, targeted radiotherapy, and chemotherapy) tend to have an impact on renal function. Note that the four cases in our sample that presented irreversible PC-AKI were patients over 70 years of age with multiple associated risk factors for 
the development of AKI, regardless of iodinated contrast administration and method of prophylaxis, as shown in Figure 1. 